\title{
Pedro Henríquez Ureña o el Pensamiento Integrador
}

\begin{abstract}
NuEstro trabajo tiene por objeto mostrar el pensamiento de Pedro Henríquez Ureña, no para disociarlo en aspectos de fragmentaria especialización, sino para hallar en él las constantes que nos permiten determinar su actitud de integrador. No resulta tarea fácil ni muy cómoda, puesto que Pedro Henríquez Ureña no nos ha dejado un libro orgánico, ni ensayos o cursos de estricta sistematización filosófica. Sus ideas están esparcidas en notas y artículos de revisión crítica, algunos recogidos en libros y otros dispersos en revistas de circulación a veces bastante restringida. ${ }^{1}$ Contamos con buenas

1 Los ensayos y notas de Pedro Henriquez Ureña que tienen especial interés filosófico son: De Ensayos críticos (La Habana, 1905), "Estudios de Lluria sobre la naturaleza y el problema social" (pp. 91-98), "Ariel" (pp. 71-80), después incluído en Horas de Esiudio (París, 1910), "Hostos" (pp. 81-98), también recogido en Horas de Estudio, y "Richard Strauss". En los otros ensayos de esa primera obra hay asimismo reflexiones de interés filosófico general. En Horas de Estudio (1910) ordena una sección especial del libro con el título de "Cuestiones filosóficas" (pp. 13.74), totalmente dedicada al análisis del positivismo y del pragmatismo. En las otras secciones del libro hay también importantes reflexiones filosóficas de orientación general; hacemos mención especial del ensayo titulado "El espiritu platónico" (pp. 253-258) y de su nota sobre "Barreda" (pp. 298-303). En sus ensayos sobre algunos poetas (Gabriel y Galán, Dario y José Joaquin Pérez) hay muestras del interés filosófico ligado a la poesía. Otros ensayos de interés filosófico publicados más tarde son: "La obra de José Enrique Rodó", conferencia leída en el Ateneo de la Juventud de México, publicada en el volumen Conferencias (México, 1910, pp. 63-83) y reproducida en posteriores publicaciones, cuyos datos precisos pueden leerse en el volumen Ensayos en busca de nuestra expresión (Buenos Aires: Editorial Raigal, 1952, p. 118) ; "La Revolución y la cultura en México" (en Revista de Filosofía, Buenos Aires, XXI, 1925, pp. 125-132), que ahora puede
\end{abstract}




\section{bibliografías de sus obras ${ }^{2}$ y valiosos ensayos que exponen aspectos diversos de su personalidad, ${ }^{3}$ pero todavía no ha tenido}

leerse en el volumen Plenitud de América (Buenos Aires: Peña, Del Giúdice, Editores, 1952, pp. 77-87), y los Seis ensayos en busca de muestra expresión (Buenos Aires, 1928). Del volumen Plenitud de España (Buenos Aires: Editorial Losada, 1940), tienen interés general y de orientación científica los ensayos: "España en la cultura moderna" (pp. 7-15) y "Los matemáticos españoles" (pp. 159-164). En sus dos obras mayores: Literary currents in Hispanic America (Cambridge, Massachusetts, 1945) e Historia de la cultura en la América hispánica (México: Fondo de Cultura Económica, 1947), además de sus ideas de orientación general, hay una copiosa información sobre la filosofia en nuestra América. Complétese con "Enrique Espinosa" (en Trapalanda, II, Buenos Aires, 1933, pp. 79-87; "Erasmistas en el Nuevo Mundo" (La Nación de Buenos Aires, 8 de diciembre de 1935) y con la reseña que hizo, con Raimundo Lida, sobre el Diccionario filosófico de José Ferrater Mora en RFH, Buenos Aires, 1940-41, números 2-3, pp. 396-398). Todavía podrían hallarse apreciables reflexiones filosóficas en "El lenguaje" ( $H u$ manidades de La Plata, Argentina, Tomo XXI, 1930, pp. 107.125), en "Veinte años de literatura en los Estados Unidos" (Nosotros, Buenos Aires, Año XXI, 1927, tomo LVII, números 219-220, pp. 353-371); en el ensayo "El espíritu y las máquinas" y en los dedicados a Velázquez que figuran en En la orilla: Mi España (México: 1922). Parte de su correspondencia, que hemos leído en la tesis de máster de Jerry E. 'Patterson, The literary criticism of Pedro Henriquez Ureña (The University of Texas, 1955), tiene también interés filosófico-estético. Suponemos que la demás correspondencia inédita que posee Rodríguez Demorizi tendrá también interés filosófico. Por último, citaremos una reseña sobre el libro Profesores de idealismo (París, 1909) de Francisco García Calderón, publicada en Ateneo de Santo Domingo, Núm. 7, agosto de 1910, que no hemos leído, pero que ha de tener abundante material, dada la índole del libro, acaso el primero en difundir en la América hispánica las ideas de William James y de idealistas franceses, alemanes e italianos de comienzos de siglo. Por lo menos así lo hacen pensar las notas que Pedro Henríquez Ureña puso a la traducción de la comunicación de F. García Calderón al Tercer Congreso Internacional de Filosofía, celebrado en Heidelberg en 1908, titulada "Les courants philosophiques dans l'Amérique Latine" (París, 1908), publicada originalmente en francés, en la Revue de Metapbisique et de Morale y luego, con las notas de P. H. U., en la Revista Moderna de México y recogida en Profesores de idealismo y en Ideas e Impresiones del mismo F. G. C. (Editorial América, Madrid, 1919).

2 Las bibliografías de Julio Caillet-Bois (RFH, VII, 1, 1946, pp. 196-210), completada por el mismo en el Homenaje a Pedro Henríquez Ureña (Letras), Revista del Círcula de Profesores de Castellano y Literatura "Arnoldo G. Crivelli", Buenos Aires, diciembre de 1956; Emilio Rodríguez Demorizi, en. Anales de la Universidad de Santo Domingo (Ciudad Trujillo, 37-38, enero-julio de 1946, pp. 55-88), y la más reciente y completa Crono-bibliografía de Pedro Henríquez Ureña, de Emma Speratti Piñero, que puede leerse en este mismo número de la Revista Iberoamericana.

3. Tratan de aspectos filosóficos de la obra de Pedro Henríquez Ureña: Andrés 
la suerte de que un investigador bien dotado le dedique un libro analítico, completo, exhaustivo, como, pongamos por caso, el que Manuel Olguín ha publicado recientemente sobre Alfonso Reyes." Quisiéramos contribuir en parte y muy humildemente a avivar una corriente de simpatía y especial atención hacia el gran maestro de la cultura hispanoamericana que fue Pedro Henríquez Ureña. Necesariamente debemos limitarnos al espacio e índole de este artículo; y como no nos será posible documentar aquí cada uno de los aspectos en que se manifiesta ese pensamiento integrador, sólo daremos los resultados, en escueta síntesis, de lo que consideramos sus ideas fundamentales. Comenzaremos por donde el mismo Pedro Henríquez Ureña empezó: la búsqueda y afirmación de una actitud personal bien definida y la integración de la misma en el pensamiento universal, como síntesis de una tradición cultural y como posibilidad de descubrimiento y creaciones futuras.

\section{ACTITUD VITAL: ENTRE LA POESIA Y LA CIENCIA}

Según nos recuerdan su hermano Max y otros testigos de la formación juvenil de Pedro Henríquez Ureña, ${ }^{5}$ una tem-

Avelino, "Pedro Henríquez Ureña", en Anales de la Universidad de Santo Domingo citado en la nota 2; Francisco Romero, "Un humanista de nuestro tiempo", en Ideas y figuras (Buenos Aires; Editorial Losada, 1949, pp. 58-69), y Aníbal Sánchez Reulet, "Pensamiento y mensaje de Pedro Henriquez Ureña", en este número de la Revista Iberoamericana.

4 Manuel Ouguín, Alfonso Reyes, ensayista. Vida y pensamiento (México, 1956, [Colección Studium-11]).

5 Parece seguro que Pedro Henríquez Ureña quedará perpetuado en la historia de nuestras letras con el perfil del humanista, del extraordinario erudito y sabio ordenador de la cultura de la América hispánica. Y, sin duda, a medida que pase el tiempo y se comprendan los ingentes beneficios de su inagotable saber, este aspecto de su personalidad surgirá cada vez más nítido y terminará por recortarlo y fijarlo definitivamente. El mismo Pedro Henríquez Ureña parece contribuir a esta consideración póstuma ,no sólo con el ejemplo de sus obras, sino también con expresas confesiones personales. Por ejemplo, en 1922, en un homenaje a José Vasconcelos dice: "Como mi dedicación principal es la literatura, y, dentro de la literatura, más que producir cosas mías, admirar las ajenas", etc. (en la revista Nosotros, vol. 42, año 1922, p. 245). En su educación más temprana encontramos confirmada una dualidad vocacional que fluctúa entre la poesía y la ciencia (véase: 
prana y bien orientada educación científica lo predispone más al análisis y al ordenamiento de la realidad objetiva y vital que a su canto o realización lírica. $Y$ aun en sus poesías de la edad juvenil, la actitud reflexiva y la construcción lógica lo acercan con preferencia a las estructuras ideales y a las grandes síntesis definidoras. Pedro Henríquez Ureña creció entre la ciencia (representada en el hogar por su padre, médico) y la poesía (representada por su madre). ${ }^{6}$ Este era un hecho común en

"Hermano y maestro", de Max Henríquez Ureña, en este mismo número). Américo Lugo, quien en 1907 lo admiraba como "el mayor poeta de la última generación", con motivo de la muerte del maestro, escribió: "Pedro creció bajo profético influjo. Fluctuó primero entre dos mundos: la poesía y la ciencia. Pagó tributo a la estirpe materna, y fue musageta en 'Lo Inasequible' y 'Al Mar', en 'Flores de Otoño' y 'Mariposas Negras'; pero tindióle al fin el pujante temperamento paterno, y ya en 1905 era el más notable crítico dominicano". (Cita E. Rodríguez Demorizi en la "Ofrenda" que sirve de prólogo a las Poesias Juveniles de Pedro Henríquez Ureña. Ediciones Espiral, Colombia, 1949, p. 8). Pero nos parece más justa la conclusión a que arriba su amigo, discípulo y albacea testamentario Emilio Rodríguez Demorizi: "Si Pedro Henríquez Ureña vivió en el mundo de la ciencia - de la ciencia literaria, preferentemente- nunca estuvo ausente de los altos reinos de Apolo: pervivian en él las inquietudes espirituales de la infancia, el dulce acento apostólico de la madre, parte enseñanza y parte poesía. Que toda la sabiduría y todos los caminos del conocimiento y de la vida tienen por meta esa luz única". (Op. cit., p. 9).

- A este respecto dice E. Rodríguez Demorizi (Op. cit., p. 8): "La poesía es el ensueño de la mañana de las grandes vidas; contiene en sombras todas las realidades futuras de la existencia... ¡Desgraciado el que no ha sido poeta una vez en su vida! Estas bellas palabras de Lamartine parecerían escritas para Pedro Henríquez Ureña, porque el sabio humanista, el maestro de disciplina tan áspera como la filología, se inició en las letras como poeta. Antes de cosechar, con manos de filósofo, los maduros frutos del pensamiento, cultivó en sus huertos interiores la flor de la poesía. Y fue siempre poeta: en lo hondo de sus escritos, aun en la parquedad de la frase en que ocultaba su emoción hay esa poesía recóndita que es quizás la más pura expresión del don divino.

Su fuente de gracia la halló en el seno de la madre poeta, de la excelsa Salomé Ureña; reposó la infantil cabeza sobre el corazón de la más egregia mujer dominicana; aspiró los hálitos de la poesía en el ambiente de la esclarecida casa solariega. Al despertatle, en la dulce mañana los versos maternales, cantó también. Había de ser poeta donde asentaba su reino la poesía. Dentro del verso conoció el sentido de las palabras y en ellas puso, con pasmo de todos, el juvenil espíritu. Así nacieron sus versos, antes de los días alcióneos de su precoz adolescencia". La poesía no abandonó nunca a Pedro Henríquez Ureña. Si dejó de escribirla en edad más o menos temprana (en 1911, a los 27 años de edad), nunca dejó de frecuentarla, como gustador de ella, o en nuevos y repetidos intentos de creación, como 
la segunda mitad del siglo XIX. Leconte de Lisle, por ejemplo, había dicho: "El arte y la ciencia, largamente separados por causas de esfuerzos divergentes de la inteligencia, deben tender en adelante a unirse estrechamente, ya que no a fundirse". Esta orientación, difundida desde Francia, se repite en otros países, y especialmente tiene un eco eficaz en escritores de Hispanoamérica. El argentino Olegario Víctor Andrade nos da una versión poco menos que textual de lo dicho por Leconte de Lisle. $Y$ afirmaciones similiares encontramos en poetas $y$ prosistas del último cuarto del siglo XIX hispanoamericano. La ciencia era la hija predilecta del positivismo, continuación, en cierto modo, del racionalismo de los siglos XVII y XVIII. La actitud opuesta estaba representada por los movimientos irracionalistas del idealismo de fin de siglo. La literatura había sido penetrada por ambas tendencias en pugna. El Parnaso llevó su afán de perfección a rigores técnicos que lindaban con la objetividad científica y la supresión casi absoluta de la personalidad. La reacción del Simbolismo llevó al extremo opuesto: frente a la apariencia, como realidad del mundo y de la poesía, se proclamó el enigma del ser y el misterio del cosmos. Un verdadero coro disconformista partió otra vez de

lo prueban sus cuentos y su magnífica reconstrucción del teatro griego primitivo, El nacimiento de Dionisos. Ensayo de tragedia a la manera antigua. Alfonso Reyes, otro admirado maestro, poeta y sabio ejemplar, al evocarlo en el más bello y emocionado retrato de su personalidad en Gratc compañia), se lamentaba en 1946 de no conocer bien los versos de su entrañable amigo, pero elogiaba la creación poemática de El nacimiento de Dionisos. Y Raimundo Lida, tan agudo siempre, nos hace esta comparación reveladora: "No es casualidad que entre los cuentos que escribió, haya alguno - para niños- no inferior a los admirables de Martî" (en "Cultura de Hispanoamérica", Cuadernos Americanos, Sept.-Oct. de 1947, p. 207). Por su parte, Enrique Anderson Imbert, si bien sostiene que el ensayo crítico "es el sello más visible de su obra", reconoce: "Pero era también un escritor de imaginación y sensibilidad: versos de sabor modernista, prosas poemáticas, descripciones de viaje, El nacimiento de Dionisos (1906) . [sic, la edición correcta es: Imprenta de Las Novedades, New York, 1916, 46 págs., aunque ya la había publicado, en febrero de 1909, en la Revista Moderna de México], "ensayo de tragedia a la manera antigua", hermosos cuentos. No escribió en esta vena bastante para incorporarse a una historia puramente literaria. Sin embargo, su sentido de la forma artística se estampó en todo lo que escribió, aun en sus trabajos de rigor técnico. Tenía una prosa magistral en su economía, precisión y arquitectura", (Historia de la literatura bispanoamericana, Fondo de Cultura Econónica, México, 1954, pág. 310). 
Francia y llenó el ámbito hispanoamericano con reacciones contra la ciencia y la concepción racional del mundo. Son célebres, a fines de siglo, las protestas de José Asunción Silva, Manuel Acuña y el Leopoldo Lugones de "la voz contra la roca" o más precisamente, de la "Introducción" a las Montañas del Oro (1897). Pedro Henríquez Ureña, lector de Naville, de Goblot y de Rickert, no puede rechazar todo lo que la ciencia tiene de positivo en la formación de la personalidad humana; pero originariamente poeta, tampoco puede negar la importancia que el misterio, la inspiración, la fantasía, la emoción nativa tienen para el mundo creador de la cultura. Y toma de ambos lo que era menester para una constitución armónica de la personalidad. De la ciencia rechaza lo que tiene de abstracción sin aplicación inmediata $\mathrm{y}$, particularmente, advierte los peligros de su especialización. Sobre todo, durante su contacto con los Estados Unidos. La lectura de obras básicas de Stumpf, Poincaré y Meyerson, le llevan a una comprensión más humanizada de la ciencia, que es -dice en 1908, hablando de Barreda- "una virtualidad que tiende a la acción"; por lo que ella tiene su razón de ser en tanto que permite cimentar una fe en la cultura como creación y aumento del espíritu. Se comprende ahora por qué Pedro Henríquez Ureña nunca vio con buenos ojos la poética del decadentismo francés, por lo menos aquella que proclamaba, por boca de Verlaine, la indecisión y lo impreciso. Frente a ellos y frente al esteticismo de Wilde, quiso oponer los aspectos afirmativos del heroísmo vital de D'Annunzio. Pero cabe recordar que nunca sometió la poesía o el arte a una función de fines comprometidos; y a pesar de esa "imaginación razonadora" que le asigna Alfonso Reyes, su concepto de la poesía se mantiene dentro de la línea platónica, con la aportación necesaria del neoplatismo humanístico del Renacimiento. En su estudio sobre Juan Ramón Jiménez (1918) dice de la poesía: “¿No es en la embriaguez donde hallamos la piedra de toque para la suprema poesía lírica, -como en el sentimiento de purificación para la tragedia? No basta la perfección, acuerdo necesario de elementos únicos: podemos concebir poesía perfecta, de perfección formal, de nobleza en los conceptos, sin el peculiar acento del canto; pero la obra del cantor, del poeta lírico, cuando la recorremos sin inte- 
rrupción, debe darnos transporte y deliquio". Lector de Nietzsche $\mathrm{y}$ de los irracionalistas del idealismo (Schopenhauer, Bergson) que se opusieron al racionalismo científico y al idealismo absoluto, Pedro Henríquez Ureña hizo suyo el precepto del autor de La gaya ciencia que dice: "ver la verdad por la óptica del artista, pero el arte por la óptica de la vida". De este modo se humanizan la ciencia y el arte, y ambas manifestaciones divergentes de la actividad humana se integran ahora en la realización de un ideal ya acariciado por Spencer y tenido en cuenta por Pedro Henríquez Ureña: a más alto desarrollo de la inteligencia corresponde siempre la mayor riqueza de sentimiento, porque la amplitud de los horizontes intelectuales, la visión de la realidad y la vida impiden toda inmoralidad y todo egoísmo, y sólo sabe darse como un acto de amor a la humanidad.

\section{CIENCIA Y FILOSOFIA. HACIA UN IDEALISMO HUMANIZADO}

La reflexión filosófica surge en Pedro Henríquez Ureña como algo que le es propio, connatural, y se desarrolla paralelamente con su vocación poética, como dos manifestaciones de una misma necesidad de descubrimiento y autorrevelación. $\mathrm{Y}$ por momentos, cuando lo acucia el rigor crítico, no duda en englobar la facultad artística dentro del espíritu filosófico, "no porque la considere subordinada, sino porque la estimo —dice en Horas de Estudio, pág. 292- como algo más que simple potencialidad creadora, de imaginación y sensibilidad ... : como una facultad elevada a la altura filosófica por el poder de sistematización y desarrollada y afinada merced a la capacidad crítica". Concluye afirmando que es axiomática ya la verdad de que todo arte elevado arraiga en la filosofía. Esta capacidad filosófica está bien manifiesta en su primer libro (Ensayos críticos, 1905), como lo prueban sus estudios sobre Ariel, Hostos, Lluria y el enfoque filosófico que hace de poetas como José Joaquín Pérez, Rubén Darío y D'Annunzio. Pero el pensamiento de Pedro Henríquez Ureña se fija, al parecer definitivamente, en la primera década de este siglo. ${ }^{7}$ Por

\footnotetext{
7 Es definiitva, en este sentido, una página de su ensayo "La revolución y la
} 


\section{entonces, si bien en Europa el positivismo era una filosofía ya superada, en América era la más difundida y aun se la aplicaba con fines oficiales. Especialmente en Iberoamérica, el positi-}

cultura en México", que publicó en la Revista de Filosofía, Buenos Aires, XXI (1925), págs. 126-127: "El nuevo despertar intelectual de México, como de toda la América Latina en nuestros días, está creando en el país la confianza en su propia fuerza espiritual. México se ha decidido a adoptar la actitud de crítica, de discusión, de prudente discernimiento, y no ya de aceptación respetuosa, ante la producción intelectual y artística de los países extranjeros; espera, a la vez, encontrar en las creaciones de sus hijos las cualidades distintivas que deben ser la base de una cultura original.

El preludio de esta liberación está en los años de 1906 a 1911. En aquel período, bajo el gobierno de Díaz, la vida intelectual de México había vuelto a adquirir la rigidez medieval, si bien las ideas eran del siglo xIx, "muy siglo XIx". Nuestra Weltanschauung estaba predeterminada, no ya por la teología de Santo Tomás o de Duns Escoto, sino por el sistema de las ciencias modernas interpretado por Comte, Mill y Spencer: el positivismo había reemplazado al escolasticismo en las escuelas oficiales, y la verdad no existía fueta de él. En teoría política y económica, el liberalismo del siglo xviI se consideraba definitivo. En la literatura, a la tiranía del "modelo clásico" había sucedido la del París moderno. En la pintura, en la escultura, en la arquitectura, las admirables tradiciones mexicanas, tanto indígenas como coloniales, se habian olvidado: el único camino era imitar a Europa. ¡Y qué Europa: la de los deplorables salones oficiales! En música, donde faltaba una tradición nacional fuera del canto popular, se creía que la salvación estaba en Leipzig.

Pero en el grupo a que yo pertenecía, el grupo que me afilié a poco de llegar de mi país a México pensábamos de otro modo. Eramos muy jóvenes (había quien no alcanzaba todavía los veinte años) cuando comenzamos a sentir la necesidad del cambio. Entre muchos otros, nuestro grupo comprendía a Antonio Caso, Alfonso Reyes, José Vasconcelos, Acevedo el arquitecto, Rivera el pintor. Sentíamos la opresión intelectual, junto con la opresión política y económica de que ya se daba cuenta gran parte del país. Veíamos que la filosofía oficial era demasiado sistemática, demasiado definitiva, para no equivocarse. Entonces nos lanzamos a leer a todos los filósofos a quienes el positivismo condenaba como inútiles, desde Platón, que fue nuestro mayor maestro, hasta Kant y Schopenhauer. Tomamos en serio ( oh blasfemia!) a Nietzsche. Descubrimos a Bergson, a Boutroux, a James, a Croce. $\mathrm{Y}$ en la literatura no nos confinamos dentro de la Francia moderna. Leímos a los griegos, que fueron nuestra pasión. Ensayamos la literatura inglesa. Volvimos, pero a nuestro modo, contrariando toda receta, a la literatura española, que había quedado relegada a las manos de los académicos de provincia. Atacamos y desacreditamos las tendencias de todo arte pompier; nuestros compañeros que iban a Europa no fueron ya a inspirarse en la falsa tradición de las academias, sino a contemplar directamente las grandes creaciones y a observar el libre juego de las tendencias novísimas; al volver, estaban en aptitud de descubrir todo lo que daban de sí la tierra nativa y su glorioso pasado artístico". 
vismo había cumplido una función fundamental de suplantar el dogmatismo de la Iglesia Católica Romana. Además de sus aspectos técnicos-científicos, base sobre la cual se construyó la era del progreso y organización nacional en nuestros principales países, el positivismo dio los fundamentos de nuestra pedagogía común y se convirtió en una doctrina social de las minorías directivas, muy de acuerdo con el naciente espíritu burgués de las jóvenes repúblicas. A comienzos del siglo, Enrique Rodó dio la primera voz de alerta sobre las consecuencias positivistas en la formación espiritual de América. La voz de Rodó venía sostenida por un amplio coro de procedencia europea, especialmente francesa, y sin duda estaba dirigida a salvar la herencia espiritual de Europa frente al avance agigantado de una nueva forma de positivismo que empezaba a invadirnos desde el Norte, paralelamente con el capitalismo norteamericano. La Revue de Métaphisique et de Morale de París (desde 1893 opositora de la Revue Philosophique, aparecida en 1876 y dirigida por Theodule Ribot, positivista) fue el principal órgano difusor de una nueva corriente idealista y humanista, metafísica y espiritualista, en cuya línea se alistó la pléyade hispanoamericana admiradora de Rodó y cuyo principal difusor, desde París, fue el peruano Francisco García Calderón. Los nuevos metafísicos reconocían a Etienne Vacherot (18091897) como el primer integrador de las antinomias entre la metafísica y la ciencia, en un libro de ese mismo título, de 1858, y, sobre todo, al creador de Le nouveau spiritualisme, 1884; admiraban a Rénouvier (1815-1903) ; seguían el "positivismo espiritualista" de Ravaisson (1813-1900), integrador de lo espiritual activo y de lo mecánico pasivo, y sobre todo, esclarecedor de la historia del pensamiento francés en su célebre Rapport sur la philosophie en France au XIXéme siècle (1868) ; proclamaban su respeto por Lachelier (1832-1918) como integrador entre naturaleza e historia, entre el sentimiento religioso y moralidad, cuyas últimas consecuencias desarrollaron Boutroux (1845-1921) y Bergson (1850-1940), el primero como expositor de la historia de la filosofía francesa a partir del momento en que la había dejado Ravaisson y el segundo como integrador de la psicología y la metafísica. Es muy posible que la figura cumbre de este momento haya sido 
Alfred Fouillée (1838-1912), el creador de las ideas-fuerzas, "que integraban en una unidad indisoluble los elementos aparentemente antagónicos de la actividad y de la pasividad, de la acción y de la inteligencia, de la libertad y del determinismo" (Ferrater Mora, en su Diccionario Filosófico). En el orden sociológico, los guías fueron, en Francia, Guyau (1854-1888), integrador de lo individual con lo social en sus fuertes ataques a la moral tradicional y a la del utilitarismo y con aplicaciones al arte y a la religión, y Gabriel Tarde (1843-1904), integrador entre la imitación e invención como base para la construcción de una sociología positiva que explique el fenómeno total de la naturaleza, pero sobre todo, visto en Hispanoamérica, como el gran defensor del espíritu latino y su propagación y triunfo en el mundo contemporáneo.

Pedro Henríquez Ureña estaba muy bien enterado de todo esto, y partiendo de lo que él llama el "idealismo crítico" (consideraba a Kant el "manantial inagotable"), ${ }^{8}$ se dedicó especialmente a justificar la función histórica del positivismo y a señalar la nueva filosofía que debía superarla. Eso es lo que hace hacia 1908 y 1909 (Horas de estudio aparece en 1910). Aquí encontramos bien definida la posición de Pedro Henríquez Ureña. Lo mismo podemos decir de afirmaciones circunstanciales deslizadas como al pasar en algunos textos de su correspondencia. Se ve claramente lo que Pedro Enríquez Ureña se proponía. En una carta a su hermano Max le declara su proyecto de escribir un libro titulado "Idealismo y pragmatismo", acaso influido por las obras de William James y las últimas reacciones producidas en Francia, especialmente en Berthelot y Bergson; y en Horas de estudio anuncia la preparación de otro titulado "La nueva filosofía". Pero es particu-

8 Antonio Caso da testimonio de las lecturas kantianas en México y del papel de Don Pedro en ese momento: "Nos trae el libro [se refiere a la Crítica de la razón pura de Kant] a la memoria días ya lejanos en que, en nuestra casa y compañia, don Pedro Henriquez Ureña, don José Vasconcelos, don Alfonso Reyes y don Martín Luis Guzmán leíamos y comentábamos a Kant en el texto de Perojo. Estas lecturas fueron para nosotros de incalculable significación y trascendencia. Pedro Henríquez Ureña poseía la versión inglesa de Max Müller, y solía agregar importantes notas eruditas a nuestras lecturas comentadas de los capítulos de la Estética " Analítica trascendentales" (en México: Apuntamientos de cultura patria, 1943, pp. 92 y 94$)$. 
larmente en la sección de ensayos denominados "Sociología" de su primer libro y en la titulada "Cuestiones filosóficas" de su segunda obra, donde su posición filosófica está mejor expuesta. Pedro Henríquez Ureña pasa revista a la filosofía, a la literatura y a otras manifestaciones del arte de la segunda mitad del siglo XIX y se sitúa en su momento histórico para señalar el contraste entre un pasado de negación metafísica, pesimismo y materialismo y un presente de nuevas luces y seguras afirmaciones. En Ensayos críticos dice:

En los albores del siglo $\mathrm{XX}$ se han hecho formidables las corrientes del pensamiento que se iniciaban en 1882. La filosofía basada en la ciencia que condena la especulación metafísica niega lo maravilloso, y busca explicación natural a los enigmas del universo, por un lado, y por el otro la voz de pensadores y artistas que predican la afirmación de la personalidad individual, como Nietzsche, el culto del yo, justamente con el valor de la vida y el retorno a condiciones más sencillas y armónicas, han influído en que el pensamiento contemporáneo, preocupado con problemas más inmediatos, "no piense en los dioses", según la frase de Goethe, y parezca marchar hacia la "irreligión del porvenir", prevista y descrita magistralmente por Guyau.

En literatura, los recientes sucesos del misticismo atávico tienen más resonancia que influencia e importancia real. Huysmans y Bourget, por caso, despiertan ahora menos interés que antes de su retorno al catolicismo; y Tolstoi y Maeterlinck, los dos escritores más influyentes de cuantos en el día deriven enseñanzas de las palabras de Jesucristo, predican casi exclusivamente doctrinas de fines sociales, prácticos, humanos.9

El positivismo había concluido por ser, en definitiva, una filosofía social, más una "estática" que una "dinámica" social, según las clasificaciones de Comte. Por eso a Pedro Henríquez Ureña le llama especialmente la atención un libro del cubano Enrique Lluria titulado La evolución superorgánica, que desarrolla un aspecto de la filosofía de Spencer. Don Pedro le dedica una amplia reseña en sus Ensayos críticos (pp. 91-98), que consideramos de capital importancia para este período del pensamiento de nuestro autor. Dice allí:

En el mundo intelectual se suceden épocas de optimismo y

- Ensayos críticos (La Habana, 1905), pp. 114-115. 
de pesimismo. Los últimos años del siglo XIX fueron de pesimismo agudo, con la influencia dominante de Schopenhauer y de Hartmann, de la poesía decadente, de la novela rusa y del drama escandinavo, con sus cuadros dolorosos, y del Triunfo de la muerte d'annunziano. Y la influencia filosófica más poderosa en ese fin de siglo, la de Nietzsche, que reunía ambas tendencias contrarias, resulta más pesimista que optimista: el pensador alemán veía en la humanidad una especie inferior, creía en la inutilidad del esfuerzo de la vida por superarse a sí misma, y para librarse de la obsesión de ese eterno en vano creó el Superhombre, encarnación de la voluntad dominadora y del individualismo anti-igualitario. El Superhombre ni siquiera había de ser feliz, puesto que debía buscar, "con su suprema esperanza, su supremo dolor", ;el ineludible dolor! Su placer favorito, la divina risa, ¿podría ser, en condiciones tales, un placer sano, una expresión de la potente alegría universal?

En contraste, estos años iniciales del siglo XX han traído una corriente cada vez más reforzada de optimismo. Ibsen, Wagner y Tolstoi, los tres máximos artistas morales de la última mitad de centuria, resultan hoy, mejor comprendidos, maestros de energía y entusiasmo. D'Annunzio, que hasta ayer se elevaba al éxtasis en la tortura moral, entona; con el fervor religioso de los antiguos vates, el magno Laus Vitae; Gorki lanza su formidable grito: iViva el Hombre!; Sudermann hace a su heroína Beata brindar, con la copa de veneno que ha de darle la muerte, por el triunfo de la Vida; Richard Strauss abandonando el escepticismo de su Zarathustra y su Don Quijote, celebra en su drama musical Fuersnoth la gloria de fuego y del amor y en sus poemas tonales La vida de un héroe y Sinfonía doméstica el esfuerzo, el trabajo, los afectos puros y plácidos; Maeterlinck predica su evangelio de fe creadora y de armonía serena.

$\mathrm{Y}$ es que, mientras los últimos metafísicos se empeñaban en probar la infinita vanidad de todo, la ciencia, la misma que minaba los cimientos de los castillos noumenales, construía las bases de un nuevo edificio cuya columna central es la fe en el Triunfo de la Vida y de la Evolución: el optimismo de Spencer y Haeckel, el meliorismo de Sully, la filosofía de la esperanza, de Fouillée, el ideal futuro de Guyau...

$\mathrm{El}$ edificio comienza a elevarse lentamente, una a cada sólida [sic] piedra la férrea armazón. ¿Quién habla de la bancarrota de la ciencia ? El nuevo pensamiento no necesita, para ser optimista, creer en el divinal destino del hombre: bástale con la existencia que conoce $\mathrm{y}$ su virtualidad inagotabe, y contesta a Schopenhauer, probándole la inutilidad del Nirvana: "El hombre desaparecerá de la tierra: otro ser se haría rey de ella, y durante millones de años la vida continuará en el planeta su marcha triunfal e inperturbable! (Novicow). 
Obra típica de este momento, por su vigoroso optimismo científico, por su absoluta fe en la vida, es La Evolución superorgánica del Dr. Enrique Lluria. Desde la desaparición de Guyau, no había sonado en la Europa intelectual una nota de entusiasmo tan ardorosamente juvenil.

Pero no se piense que la fe que anima este libro se apoya en la bondad de la vida social presente. Observando los males que azotan la sociedad moderna, Lluria ha sentido el deseo de contribuir a formar la idea de un progreso más efectivo que el contemporáneo y más acorde con las leyes naturales de la evolución. Y para poner sus ideas al servicio de la humanidad, ha apresurado la publicación de este estudio de "la naturaleza y el problema social", que, con ser apenas el esbozo de un sistema sociológico a base biológica, es por su vigorosa originalidad y su altura de concepto, digno de la acogida entusiasta que ha obtenido entre la intelectualidad española y de los elogios que le tributa en el prólogo el maestro del autor, el eximio Ramón y Cajal, intelectualidad verdaderamente genial que a un profundo saber une el don maravilloso de un estilo que convierte la ciencia en poesía. ${ }^{10}$

Pedro Henríquez Ureña hace una exposición de la obra de Lluria, cuyos detalles no interesa exponer aquí. Pero creemos necesario resumir sus conclusiones más importantes:

El proceso continuo de la vida es, según la definición de Spencer, la adaptación de las relaciones internas a las externas. $\mathrm{Y}$ como ya observó el mismo filósofo inglés, la nueva evolución del ser que representa el más alto grado de evolución en el planeta, será una mayor adaptación y coordinación de acciones, que necesariamente se realizará en el sentido de un desarrollo superior de la inteligencia y de los sentimientos.

Hasta aquí, el joven pensador español está en perfecto acuerdo con el monismo de Haeckel y el evolucionismo de Spencer. Pero, al considerar los fenómenos del mundo superorgánico, aspira a ampliar la obra de sus predecesores y rectificar muchos conceptos erróneos hoy en boga.

Ante todo, quiere desterrar de la ciencia social la ley de lucha establecida por Darwin para la biología y luego erigida en principio sociológico que han llevado a la exageración por distintas vías, Nietzsche y Gumplowicz, y que constituye hoy una idea-fuerza en los pueblos de educación teutónica. Fouillée piensa que la concepción opuesta, "la unión para la vida" es propia de los pueblos llamados latinos. $\mathrm{Y}$ en esto es ciertamente donde 
los sociólogos dan más decisiva preponderancia al principio de la solidaridad sobre el de la lucha en la vida superorgánica.

Parece que Lluria había tomado esto de Engels: "Siendo la explotación de una clase por otra la base de la civilización, su evolución se realiza en contradicción constante. Cada progreso de la producción es al mismo tiempo un retroceso en la situación de la clase oprimida ,es decir, de la mayoría”. Partiendo de este razonamiento semejante al de Engels, -comenta Don Pedro - Lluria considera evolución aberrante la de la sociedad moderna:

Todas las enormes desigualdades e incongruencias de la vida contemporánea son productos de ideas y prácticas erróneas con que el hombre ha falseado las leyes naturales. El capital, el dinero mismo, la propiedad, tales como se conciben hoy, todo sistema económico, en fin, es nocivo al desarrollo efectivo y completo del organismo social, y, por consecuencia, de cada organismo individual. Los males reinantes -el pauperismo, la miseria fisiológica y las enfermedades, la degeneración física y psíquica- están tan extendidos que requiere un tratamiento rápido y certero.

Lluria tiene alta fe en la ciencia y fe aún más alta en la Vida, cuya virtualidad es tal que secundará con creces cualquier rectificación de un proceso aberrante. Conocidos los factores de la evolución - adaptación, selección y herencia- debe estudiárseles y ayudárseles a fin de reintegrar al hombre en el proceso evolutivo de la naturaleza. Así como hemos sabido sustituir la lenta selección natural, cuyo agente es la lucha biológica, con la selección artificial de las plantas de cultivo y los animales domésticos, hasta para obtener cualidades morales, debemos sustituir las desastrosas luchas sociales, que primero estimulan pero al fin agotan la energía de las razas, con el trabajo universal, libre de las aberraciones de la propiedad y el capitalismo. El amor, medio natural de selección en la vida superorgánica, será la base de la sociedad del porvenir.11

La base de esta "perfección" futura será la selección psíquica, que llevará a toda la sociedad del porvenir a la felicidad, dice Lluria. Y Pedro Henríquez Ureña, que en uno de sus ensayos sobre Rodó adopta la idea de los "hombres repre-

11 Ibid., pp. 95-97. 
sentativos" como conductores de pueblos y creadores de cultura, agrega: "La fórmula del porvenir, que es deber de la Sociología esclarecer, será la socialización de la naturaleza por la humanidad". Lo que Lluria y Pedro Henríquez Ureña piden es una integración de lo individual en lo social, como algo natural y necesario, o, lo que parece ser lo mismo, un "equilibrio de la existencia colectiva". Ambos creen en la cienca para lograr este fin y parecen sostener que este equilibrio no se ha logrado

no porque las realidades científicas sean, ni con mucho, oscuras, sino porque la razón común ha seguido el mismo antinómico e irregular desarrollo de la vida económica: el intelecto de la masa social, sin excluir las comunidades más civilizadas, contiene, en incongruente mezcla, verdades aprendidas principalmente en las exteriorizaciones prácticas de la ciencia, y conceptos absurdos, supervivencias hereditarias o atávicas, aparecidos según la gráfica expresión de la tragedia isbeniana. Por tanto una de las necesarias carreras preparatorias de la realización de una vida social más acorde con las leyes naturales de la evolución, ha de ser la racionalización del pensamiento de las mayorias por medio de una educación positiva, científica, destructora de la rutina, "que es a la inteligencia lo que la inercia a los cuerpos brutos". Así preparados los cerebros para las concepciones reales y justas, percibirán más clara la necesidad de reformas cuyo resultados sean una vida fisicamente normal y sana que tienda espontáneamente a la más alta actividad y un desarrollo superior de la moral científica, cuyo ideal es la armonía. ${ }^{12}$

Desde este momento (1904), toda la obra de Pedro Henríquez Ureña estará dedicada a combatir toda clase de determinismos positivistas, naturalistas o materialistas. Los comentarios a las conferencias de Caso (le critica su tímido anti-positivismo, si bien Caso se decía intelectualista) y sus estudios sobre el pragmatismo tienen ese fin. Con respecto al papel de Comte en la historia de la filosofía da esta justa apreciación:

La clasificación de las ciencias, que es aceptable como serie histórica y en parte como serie lógica, sirvió como punto de partida a la constitución de la enciclopedia contemporánea. Comte

12 Ibid., p. 97, 
no aportó a la filosofía ninguna noción esencialmente nueva, sino que puso a su disposición, en mejor orden que antes, el conjunto de las ciencas, como lo había deseado Novalis y lo habían ensayado pensadores del siglo XVIII; su papel tenía que dejar bien pronto de ser activo y convertirse en histórico; así lo impuso la posterior transformación de las ciencias, provocada en gran parte por irrupciones de metafísica que habrian escandalizado al fundador del positivismo. (Prezzolini propone que se escriba una mitología de las ciencias contemporáneas).13

El principal papel de Comte no es otro que el de un "vulgarizador genial", que supo "llevar a las mayorías la agitación filosófica, en forma de especulaciones sencillas, democratizó la razón y proclamó que, ... .en filosofía ... nadie queda excluido"; además, "puso en auge los métodos científicos y perfeccionó la pedagogía contemporánea". En cuanto a la sociología, "señala una superioridad de su filosofía histórica sobre la de Hegel en su estudio de correlación entre las diversas actividades sociales". ${ }^{14}$

Su ensayo sobre "EI positivismo independiente" completa al anterior:

Mientras el realismo se hacía cada vez menos crítico y más intolerante en boca de sus divulgadores, la corriente del idealismo... seguía ganando las altas esferas y venció por fin a su rival. Al terminar el siglo XIX, aunque el gran público se dedicaba a leer El enigma del universo de Haeckel con un interés que no había despertado ningún otro libro científico ni filosófico desde el Origen del hombre, de Darwin, los críticos de todos los bandos, lo mismo el Cardenal Mercier que Fouillée o Windelband, podían afirmar que el positivismo aceptado por la mayoría de los hombres de ciencia había anclado defintivamente en el criterio idealista. ${ }^{15}$

Pedro Henríquez Ureña proclama la necesidad de una vigorosa defensa de todas las manifestaciones filosóficas que pudieran conducir a un nuevo idealismo y a una vuelta a la metafísica. Y está claro que responde a una actitud filosófica general de la segunda mitad del siglo XIX: la alemana e in-

13 Horas de estudio, pp. 43-45.

14 Ibid., pp. 35-36.

15 Ibid., pp. 46-47. 
glesa (además de la francesa ya mencionada y del naciente idealismo italiano representado por Croce) que reaccionó contra el naturalismo de Haeckel y Darwin, contra el positivismo de Spencer y Comte y contra el determinismo de Taine. Esta actitud procedía de Dilthey y se aseguraba, a fines del siglo, con Simmel y Scheler especialmente. En Francia, repetimos, el renacimiento metafísico e idealista tenía su órgano espiritual en la Revue de Métaphisique et de Morale, y por boca de Bergson, se sostenía que en el mundo había entonces dos países representativos de la filosofía de mayor porvenir: Francia y E. U. De ahí el interés por William James.

La sagacidad de Pedro Henríquez Ureña al situar a Stuart Mill en la historia de la filosofía, le permite anticipar apreciaciones que hoy se tienen por váljdas:: Mill, al colocar el problema epistemológico en los lindes del escepticismo, lo conecta con el pensador norteamericano William James, quien va a "justificar el conocimiento dándole valor de acción ya que no de realidad. El pragmatismo, pues, es hijo del idealismo crítico; aunque éste, en Mill, cuando quería vencer las limitaciones del empirismo, entraba involuntariamente, según indica Benno Erdmann, en el terreno de la necesidad psicológica". ${ }^{16}$ Pedro Henríquez Ureña supo ver la base de psicología asociacionista, con mezcla de lógica conceptual, que hay en la filosofía de Mill. Y cuando se cree que aquél sistema fuera a caer en algunas de las formas del irracionalismo de fin de siglo, nos aclara:

En él se esboza la hipótesis de Lotze que se cita como una de las formas de la filosofía de la contingencia, la posibilidad de que aparezcan elementos nuevos, nuevos comienzos, los cuales no escaparían al imperio de la ley, sino que tendrían la suya propia. (Esto debería llamarse en realidad la teoría de lo imprevisto). Lejos de su pensar, empero, la concepción del universo como esencia irracional, discordante o contingente en su manifestación, que sólo por necesidad estética o por necesidad práctica ensayamos concebir bajo el dominio de leyes: concepción que bajo diversas formas, incipientes o precisas, oscuras o conscientes, se insinúa en la filosofía alemana, desde los problemas de la dialéctica trascendental de Kant, a través del romanticismo (Schelling, Schopenhauer), hasta Lotze, no sin 
alcanzar a Nietzsche; penetra en Francia con las corrientes iniciadas por Ravaisson y Renouvier, y hoy lucha francamente, bajo armaduras diversas (pluralismo pragmático, bovarismo, evolución creadora de Bergson, teoría de la contingencia), con las concepciones intelectualistas de unidad y necesidad fijas e inmutables. 17

Como se ve, Pedro Henríquez Ureña busca una integración entre la contingencia y la ley, entre el irracionalismo y una racionalidad que no se pierda en el intelecto, sino que se consagre en la actividad de la vida. De esta manera se aparta ya de Boutroux y sigue más bien la doctrina de las ideasfuerzas de Fouillée, con la cual es evidente que quiere reemplazar la unidad materia-fuerza del positivismo. No debemos olvidar asimismo el origen platónico de la actitud de Don Pedro, un Platón que pudo espigar a través del mismo Fouillée, en su famoso libro La philosophie de Platon (París: Hachette, 1888-1904), o acaso a través de Walter Pater, cuyo libro Plato and Platonism es precisamente de 1909. Pero no debemos olvidar tampoco la exposición que Menéndez y Pelayo había hecho de Platón en el primer volumen de la Historia de las ideas estéticas en España (1883), por el gran respeto que nuestro autor tenía hacia el ilustre crítico español. No titubeamos en afirmar que la actitud integradora de Pedro Henriquez Ureña pudo venirle del mismo Menéndez y Pelayo, quien había sostenido ya el realismo de las ideas de Platón y había señalado con precisión las relaciones con el discípulo Aristóteles. Las incitaciones de Menéndez y Pelayo, Walter Pater y Fouillée se avenían bien con el espíritu del neo-platonismo renacentista y la integración de Platón y Aristóteles que habían hecho los humanistas españoles (recuérdese especialmente a Fox Morcillo). La filosofía moderna conecta aspectos del Renacimiento (el empírico-científico y el racionalista subjetivo) con la filosofía del siglo XVIII y el idealismo crítico, hasta la idea absoluta de Hegel y otros absolutismos del romanticismo alemán; pero, sobre todo, tuvo sus efectos más estrechamente dogmáticos y anti-metafísicos en el positivismo de la segunda mitad del siglo XIX. Frente a todo esto em- 
pezaron a reaccionar las filosofías de la vida y de la cultura, con figuras como Dilthey, Windelband y Rickert a la cabeza, sin descartar, por otra parte, actitudes pre-existencialistas como las de Kirkegaard y otros. El nuevo idealismo alemán, que Stirling, Green, Bosanquet y Bradley impusieron en la Inglaterra de fin de siglo, y en cierto modo, Royce, en Estados Unidos y Croce en Italia, tuvo su manifestación esencialmente espiritual y vital (de cuño metafísico platónico) en Alfred Fouillée y Ortega y Gasset, en Francia y España, respectivamente. Pedro Henríquez Ureña debe situarse en esa actitud filosófica, de idealismo espiritual integral : es decir, en el idealismo de los ideales, de concepción netamente hispánica, que José Ferrater Mora ha opuesto al idealismo de las ideas, en el sentido meramente racional o intelectual de los siglos XVII y XVIII. ${ }^{18}$

$Y$ siguiendo firme en nuestra creencia de que el pensamiento de Pedro Henríquez Ureña fue esencialmente integrador, nos atrevemos a insinuar que en él podríamos hallar un antecedente hispanoamericano a la teoría de la "razón vital" de José Ortega y Gasset; con lo cual, reconoceríamos, junto con la aportación literaria del modernismo, esta otra, de carácter filosófico, como contribución de la originalidad de nuestra América al mundo hispánico y a la cultura universal. Esto explicaría también la constante defensa de los valores hispánicos que hizo Pedro Henríquez Ureña.

\section{CONCLUSION}

No cabe duda de que el hombre Pedro Henríquez Ureña - artista y pensador-venía precedido de un innato sentido de la universal, aquel ritmo y armonía de lo eterno de que hablaba Platón, su maestro favorito; y así lo vemos desde una edad tempranamente madura ya definido con claridad hacia una integración de lo individual y de lo temperamental con los valores permanentes de la cultura. Originalidad y tradición, creación y erudición, ser y mundo, lo particular y lo universal,

18 José Ferrater Mora, España-Europa (Santiago de Chile: Ediciones Cruz del Sur, 1942). 
lo concreto y lo genérico, lo ideal y un bien entendido realismo práctico, tales son los polos que se atraen con imponderable fuerza de integración y equilibrio. Nos parece que toda su obra es un esfuerzo ingente por superar cualquier forma de dualismo, cuyo fracaso es evidente que se cumple como una exigencia de sistema, como resultado inevitable de su propia y convencional rigidez. La realidad, objetiva o subjetiva, es siempre una y existe allí donde puede manifestarse como un acto de vida: es decir, creación, expresión, actividad que recibe y que es capaz de nutrir constantemente otras realidades. En 1883 decía Dilthey: "La idea fundamental de mi filosofía es el pensamiento de que hasta el presente no se ha colocado ni una sola vez como fundamento del filosofar a la plena y no mutilada experiencia, de que ni una sola vez se ha fundado en la total y plena realidad". Y Pedro Henríquez Ureña, en 1907, al comentar el histórico ciclo de la Sociedad de Conferencias de México, nos da esta concepción del espíritu filosófico: "La principal facultad por ellos revelada es, a mi ver, espíritu filosófico. Filosófico, si se quiere, en significación más extensa de lo que es usual: espíritu capaz de abarcar en convicción personal e intensa los conceptos del mundo y de la vida y de la sociedad, y de analizar con fina percepción de detalles, los curiosos paralelismos de la evolución histórica, y las variadas evoluciones que en el arte determina el inasible elemento individual". ${ }^{19}$ De allí su centro irradiador, auténticamente poético, que convoca y atrae a su ser reflexivo y organiza su personalidad definitiva. Pedro Henríquez Ureña, que nace poeta, se revela y afirma en el mundo de la cultura como pensador y crítico y concluye siendo el gran organizador de complejos ideales, o, en definitiva, para nosotros, el orientador de América.

Asombra en un hombre de letras, tal como ahora lo vemos, la seguridad con que abarca amplísimos panoramas del saber, los penetra y vuelve de ellos con la idea clara y precisa que había de servirle para lo que realmente necesitaba o debía ser. Sólo quien conoce bien el pasado se afirma en el presente y marcha seguro hacia el porvenir. La cultura, en los diversos 
momentos en su historia, tiene valores temporales y otros que son permanentes. Los unos definen el saber histórico y caracterizan épocas y condicionan períodos; los otros atañen más a la eternidad del hombre y de sus creaciones. Pedro Henríquez Ureña tuvo una capacidad especial para deslindar unos de otros y hallar seguros rumbos en los momentos de más alto prestigio del pasado cultural; sobre todo en el pasado inmediato y en los momentos del desarrollo cultural coetáneo a su formación, supo distinguir siempre lo que estaba muriendo de lo que engendraba una nueva dinámica de porvenir. Por eso pudo ser el vigía de un mundo de luces interiores y un espectador siempre conmovido de esa encrucijada que aun estamos viviendo; el siglo XIX, que entregaba parte de su alma y de su corazón al idealismo de la razón, al experimentalismo de la ciencia, a la abstracción de las leyes generalizadoras y a la comodidad de la técnica, y el siglo XX, que pugna por hallar una nueva noción del espíritu para reintegrar al hombre a su plena condición humana.

Precisamente es ésta la actitud filosófica fundamental que podemos admirar en Pedro Henríquez Ureña: un radiante idealismo del espíritu, optimista, afirmativo y creador, arraigado en la creencia de una realidad concreta, perfecta o perfectible - realidad metafísica esencial y objetiva- y la seguridad de que en ella se afirma lo humano como una manifestación del bien y del amor, únicas formas posibles de la dignidad del hombre y de la convivencia humana. En ello encarna su fe, que impulsa la razón para garantizar y hacer comunicable lo bello y lo perfecto. Como su maestro Platón pudo decir: Yo nada sé fuera de una exigua disciplina de Amor (Theages); o bien, ni en los cuerpos ni en otra cosa alguna sino sólo en el alma, se da lo bueno y lo bello (Filebo).

Es evidente que quien de este modo se acercaba a la vida, al hombre y a lo humano, con esta actitud filosófica quería dar una respuesta a todo el ciclo de la filosofía moderna - la que va desde Descartes hasta las postrimerías del siglo XIX. Esa filosofía se había fundado en la razón abstraída en el intelecto, la idea absoluta y la experiencia resuelta en la ley científica y la técnica aplicada. Todo esto venía a someter la vida a la naturaleza, los sentimientos a la inteligencia pura 
o a la conciencia vacía; abstraía la realidad, negaba las vivencias y el conocimiento de la "cosa en sí", afirmaba la actividad en el fenómeno, las apariencias y lo convencional, $\mathrm{y}$, por fin, negando las relaciones de lo inmediato con la verdad esencial, negaba también las posibilidades de un más allá del espíritu, del misterio, en fin, de la metafísica y del arte. Concluía, en suma, en los dos terribles males que la Europa moderna nos ha dejado como herencia de un mundo sin fe, sin amor y sin ideales: el individualismo egoísta de todos los despotismos ilustrados y el pesimismo que engendran todas las formas de lucha y de destrucción. Pedro Henríquez Ureña recibe esta herencia con los estertores del siglo XIX, después de una procesión de fracasos filosóficos y vitales que se llaman: empirismo, racionalismo, idealismo absoluto, cientificismo, transformismo, evolucionismo, organicismo, mecanicismo, positivismo, determinismo, naturalismo, logicismo, neokantismo, sociologismo, utopismo, agnosticismo, decadentismo, y qué sé yo cuántos "ismos" más todos, al parecer nacidos del subjetivismo y del individualismo modernos. Ante esta vertiginosa carrera de caídas que intentan una sistematización, más que de la realidad, del caos tendido sobre ella por esas mismas sistematizaciones; del hombre, Pedro Henríquez Ureña tiene la vislumbre de que un solo camino sería correcto: la vuelta a lo humano. La insistencia con que utiliza esta palabra -en todas sus formas gramaticales: sustantivo, adjetivo, verbo, adverbio_ - prueba la fidelidad con que se aferra a ella. Y si no se aplica a una definición precisa de lo que él entiende por "humano", es porque resulta obvio - harto ya de definiciones, de leyes y sistemas - que una realidad basta con que sea vivida para que resulte humana. Los objetos del mundo y del espíritu, la experiencia, la razón, la idea, las formulaciones de la ciencia, los sistemas, las instituciones, todas estas cosas han perdido hoy su eficacia porque ellas forman parte de un cuerpo muerto de principios y estructuras que existen fuera y separados de la vida. Salvar, pues, la vida en su inmanencia más inmediata, necesaria, elemental y hasta biológica, con una nueva concepción de los organismos sociales, políticos y económicos, y salvar luego las formas superiores que la vida crea como atributos de lo humano, como razón de ser del alma 
y del espíritu, es lo que urge a este humanista moderno, actual y americano, como acertadamente ha sido llamado. ${ }^{20} \mathrm{Y}$ he aquí su mensaje, mensaje de integrador, repito, en un proceso concreto que va de lo individual a lo general y que vuelve a la armonía total de la persona: integra erudición y saber en una cultura viva, activa, en la que, a su vez, se integren el individuo creador y la tradición, lo individual, particular y personal, con lo universal, ideal y permanente; lo subjetivo con lo objetivo; la contemplación y la acción; el intelecto y la sensibilidad; la vida y el arte. $\mathrm{Y}$ todo esto impregnado de una fuerte esteticismo muy renacentista, pero también muy postrealista y postpositivista de fines del siglo XIX y principios del XX. Por fin, hijo de América, del mundo hispánico, o, si se quiere, con más amplitud: latino, busca una integración de la cultura incipiente de Iberoamérica con la europea y la norteamericana, salvando siempre las formas originales y creadoras que nos son propias. ${ }^{21}$ Tal fue, en última instancia, el máximo esfuer-

20 Véase: Francisco Romero, "Un humanista de nuestro tiempo", en Ideas y Figuras, op. cit., y Antonio Castro Leal, "Pedro Henríquez Ureña, humanista americano", en el Boletín bibliogrático mexicano, de México, 31 de julio de 1946.

21 Creemos que del humanismo, suma y síntesis del espiritu clásico, tomó Pedro Henríquez Ureña su pasión por los ideales del espíritu y el sentido humano de los mismos, y que de su confrontación con la cultura moderna accedió a tomar de ésta los instrumentos que podían llevar a aquellos ideales a un mayor acrecentamiento y provecho. De ahí, también, su integración entre la cultura clásica y la moderna, y la latina con la anglo-norteamericana. Partamos de la idea del humanista moderno de Francisco Romero y veamos cómo Pedro Henríquez Ureña, si en un momento prestó oídos al llamamiento de Rodó, supo darle sentido y ajustarlo a las necesidades que la circunstancia histórica requeria. Dice Romero: "El humanismo consiste en la asimilación de la cultura, en su incorporación al espíritu en los términos de una profundización y potenciación de lo esencial humano. La humanidad crea la cultura en un esfuerzo plural nunca interrumpido; la cultura of rece aspectos puros, libre de cualquier escoria, en los que se manifiestan las capacidades y los anhelos más elevados del hombre, y otros de menor dignidad, de índole práctica, utilitaria. El humanismo es la concentración personal de aquel primer aspecto o sector de la cultura, su reconducción al hombre, el enriquecimiento del individuo con todos los bienes de orden superior producidos por la especie, la animación del tesoro disperso al ser encarnado en una persona humana". F. Romero, en Ideas y Figuras (Buenos Aires: Editorial Losada, S. A., 1949.

El humanismo, así entendido, se fijó en los momentos más originales y lúcidos del Renacimiento y consistió en un modo de captar y hacer propios los contenidos sustanciales de la cultura greco-romana, considerada clásica, a la par que modelo 
zo de su labor, cuyos resultados dio en Seis ensayos en busca de nuestra expresión (1928), Literary Currents in Hispanic America (1945) y La cultura en la América hispánica (1947).

\author{
ALFREDO A. ROGGIANO. \\ State University of Iowa. \\ Iowa City, Iowa.
}

del más alto prestigio de los valores creados por la humanidad hasta esa época. Pero esa apropiación del saber consagrado no era mera acumulación erudita, sino una recepción que se asimilaba, depuraba y era materia de nuevas creaciones. El humanista, tal como se ha fijado su imagen en los siglos XV y XVI, era a la vez un receptor $y$ un creador de cultura. A partir del siglo xvir, con el advenimiento de una filosofía del individualismo subjetivo y de las nuevas concepciones de la vida moderna, desaparece esta idea del humanista como integrador de cultura y creación, y empiezan a fragmentarse la realidad y las actividades del hombre en un especialismo cuyas consecuencias no hace falta reiterar aquí. Pedro Henríquez Ureña ha señalado la gravedad de este hecho, llevado a sus últimas consecuencias con el positivismo científico y, sobre todo, con su aplicación técnica en los Estados Unidos. "La cultura y los peligros de la especialidad" se titula uno de sus más vehementes ensayos, publicado en la revista Nosotros, de Buenos Aires, en septiembre de 1922. (Año XVI, Núm. 160, pp. 47-54. Véase también "El espíritu y las máquinas", citado en la nota 1). Critica allí el especialismo norteamericano y, fiel a su tradición latina, clásica y renacentista, aboga por una cultura integral, humanista, que sea fuerza viva de saber y creación, única forma de devolver al hombre su jerarquía universal y la consolidación de sus valores permanentes. Pero como hombre que está ya de vuelta de ese saber acumulado en los hechos y sus relaciones, no desdeña el método que a ello conduce, en tanto que sea usado para una precisión del saber, su clasificación, ordenamiento, modo de aprovecharlo y dirigirlo hacia su producción. Por eso, ya en 1904, toma posición ante el Ariel de Rodó mediante una actitud sabiamente integradora, en la cual, si reconoce la verdad de la crítica de fondo que hace Rodó a los Estados Unidos, no deja de advertir los aspectos positivos que aquí pueden hallarse. "Pero por encima de sus tendencias prácticas - dice-aquel pueblo sustenta un ideal elevado, aunque distinto de nuestro ideal intelectualista [lo subraya]: el perfeccionamiento humano, que tiene por finalidad el bien moral [también subrayado por él] y debe traducirse socialmente en la dignificación de la vida colectiva". (Ensayos críticos, pp. 71-80). Más tarde, en 1913, en un nuevo ensayo sobre "La obra de Rodó" publicado también en la revista Nosotros de Buenos Aires (Año VII, Núm. 45; vol. 9, 1912-1913, pp. 223-238), abarca en amplio cuadro todo el panorama de la cultura y se fija como antes en América y particularmente en "Nuestra América" y en sus hombres representativos, con un fin evidentemente integrador. En Seis ensayos en busca de nuestra expresión (1928) dirá la forma cómo se hará la integración de América para que ésta construya su destino propio. 